\title{
Translation as an Alternative to a Language-Based Vocational Course at the Undergraduate Level
}

\author{
Raden Arief Nugroho ${ }^{1}$, Achmad Basari ${ }^{1}$, Valentina Widya Suryaningtyas ${ }^{1}$, Nina Setyaningsih ${ }^{1}$, Setyo \\ Prasiyanto Cahyono ${ }^{1}$, and Anisa Larassati ${ }^{1}$ \\ ${ }^{I}$ English Study Program,Universitas Dian Nuswantoro, Imam Bonjol 207, Semarang, Indonesia
}

\author{
arief.nugroho@dsn.dinus.ac.id
}

Keywords: Translation, Vocational Course

\begin{abstract}
Linguistics has often been regarded as a theory-based discipline since its development in the 18th century. In the context of education in Indonesia, the authors identify that most of undergraduate level language-based study program takes form as a theoretical course rather than vocational one. If there is one, based on our search in the Indonesian Government Higher Education Database, rather than developing the potential of linguistics branches to the fullest in the core of curriculum, universities tend to incorporate other academic disciplines in their language-based vocational curriculum, e.g. the inclusion of tourism and banking fields of study in the curriculum. This makes the purity of linguistics as a science shades, thus public's misconception that linguistics is merely an inapplicable science is inevitable. Through a critical literature review, the authors aim to promote translation as an alternative to a language-based vocational course at the undergraduate level. We are assured that translation consisting of audio, visual, written, and sign translations can captivate the essence of linguistics in its application. In this article, we discover that each linguistics branch, from the study of sounds to generative linguistics, contributes to the success of translation. Hence, translation can benefit from theoretical linguistics ending linguistics to highly value something it owns and turn theoretical linguistics into applied one. However, due to the study limitation, we have not been able to identify the perception of stakeholders, either university academia members or graduate recruiters, about this issue. Therefore, further study regarding the efforts to overcome the limitation needs to be generated.
\end{abstract}

\section{INTRODUCTION}

As a science, linguistics has often been regarded merely as a theory-based discipline. This is supported by many linguists who define linguistics as "a scientific study of language". Since it is regarded as scientific, many linguistic studies are associated the discipline as a theoretical instead of an applied one.

In the context of global industrialization development, there will be a high demand for applied science majors. Such a phenomenon is widely discussed in printed and online mass media. Some cases in points include the article discussing Indonesian sailors who are threatened to be unemployed since they do not have applied science knowledge in sailing field (www.ekonomi.bisnis.com), and the article alleging the demand of industries for vocational education graduates (www.nasional.sindonews.com). The condition seems to be threatening the existence of linguistics in the future. The authors concern that the role of linguistics in industries will be disregarded if it does not give any significant contributions to the development of industries. In this context, we refer "industry" as the manufacture of goods and the commercialization of services which either related or unrelated to language.

Regarding this issue, some linguistic scholars have stated that applied linguistics is the answer of the problem. However, according to Harris (2001:100), applied linguistics was initially developed to study the use of language in a classroom context. This indicates that in essence, applied linguistics actually emerged to accommodate the issues in language teaching. We further argue that Harris' opinion was not necessarily correct, since the discussion and research in the field of applied linguistics have actually been developing in more than merely classroom context. It can be seen from the increase in the numbers of journals of applied linguistics, ranging from the English Teaching Journal (first published in 1946), Language Learning 
(1948), TESOL Quarterly (1966), Studies in Language Acquisition (1978), English for Specific Purposes (1981), and so on and so forth.

Of those journal titles mentioned, however, at least from the 90 s to $90 \mathrm{~s}$, there has not been any that mentions the relation of the journals and real-world industries. This is actually implied by Harris (2001:101). He states that the leading current applied linguistics journals such as AILA and AAAL mainly only elaborate the aspects of language education, language loss and gain, bilingualism, discourse analysis, psycholinguistics, language policy and planning, etc. There have been no applied linguistic researches that specifically concern on the role of language in real world industries, at least in the early 2000s.

The concerns on linguistics unpopularity are not counterbalanced by the efforts of academicians to relate the potential of linguistics with the industries. Based on our observation, there is a possibility that this will impact in the low interest in studying linguistics, as what has happened in Columbia University in the City of New York. The university closed its linguistics department since there were not many candidates who were interested in taking the major (www.features.columbiaspectators.com). The online article mentioned that the main reason for closing the linguistics department was that "The department was stuck in the past. They had no interest in seeing the department grow".

What about the context in Indonesia? Based on the keywords search on "English" and "Linguistics" conducted by the authors in the Database of Higher Education (PDPT), the "English" keywords are found in 766 study programs and 30 study programs are with the term "Linguistics" meaning that almost $90 \%$ of the study programs are Strata One (S1), Strata Two (S2) and Strata Three (S3). There is one study program in the form of Diploma Three (D3), four study programs in the form of Strata Two (S2), and one study program in the form of Strata Three (S3). From the advanced observation conducted, we find some findings that almost all study programs in the form Strata One (S1), Strata Two (S2), and Strata Three (S3) focus their study on the science of applied linguistics. This means that most study programs do not try to overcome the problems in industries where actually they need real and applicable solution from linguistics. We are concerned that the case occurs in Columbia University in the City of New York can also occur in Indonesia if study program managers do not make any strategic moves.

Fortunately, many study program managers in Indonesia are aware to the problem. At the moment, there are many study programs try to connect linguistics with developing industries in Indonesia, for example tourism (Nugroho et.al, 2017). Many study programs, now, often includes it in their curriculum. Although this connection is a careful effort to find the potential relevance of linguistics and industries, the authors argue that linguistics is prone to lose its purity of science, because the linguistics elements used in the curriculum are generally only the language, not linguistics. This is commonly referred to as the application of Language for Specific Purpose.

The authors argue that the effort to connect the linguistics to industries while maintaining the purity of its knowledge or science has been developing since the past decade along with language industry development, namely translation industry which includes interpreting and localization (Cabrera, 2017: 2 ). We consider that the industry can be classified into a creative industry where its existence continues to grow in accordance with the characteristics of globalization, for example internationalization of books with its translation from their local languages into global ones, the provision of game facilities with bilingual access and others.

We argue that through the role of translation, linguistics can remain dignified in maintaining the purity of its knowledge. The translation industry, we believe, can enter to the area of goods manufacturing and commercial services, for example the translation of manuals for making goods and the translation tourism brochure of tourist destination or tourism area which is closely related to the commercialization services.

Thus, translation can be benefit from the potential of linguistics branches. Based on the previous reasons, the benefit of linguistics in the translation industry and its effort to make translation as a linguistics or language-based vocational course at the undergraduate level becomes the main topic and discussion in this article.

Why is the undergraduate level? We consider that this group is the largest group of post high school students and almost all employment recruiters and job recruiters prefer using undergraduate graduates as the primary and mandatory requirements to enter to a professional white-collar working field (www.cbsnews.com). 


\section{REVIEW OF RELATED LITERATURE}

In this section, the authors divided the discussion of the related literatures in two parts. The first part discusses literatures on linguistics and the second part discusses literatures related to translation studies. It aims to unveil the potential of each field of study and to draw the connecting line between both of the fields (as discussed in chapter 4).

\subsection{Linguistics}

Linguistics or the scientific study of language, analyzes language from three aspects, i.e. from its form, meaning, and context. Linguistics explores the form of language from its smallest unit called sounds. The sounds being explored in linguistics are both speech sounds and non-speech sounds. Moreover, the studies of sounds in linguistics are divided into two branches called phonetics and phonology. Phonetics is often associated with investigating the production of speech sounds through human's physical organs, while phonology discusses the function of sounds and their role as a signaling unit in a language.

Crystal (1987:15) categorized phonetics and phonology as the branches of linguistics which deal with the pronunciation aspect of a language. Furthermore, when it deals with the grammatical aspect of a language, the related branches of linguistics are called morphology and syntax. Morphology is a branch of linguistics which concerns with the word formation and composition, while syntax concerns with the formation and composition of phrases and sentences. Finally, the study of language which relates to the aspect of meaning is accommodated by the branches of linguistics called semantics and pragmatics. In the diagram of linguistics branches introduced by Crystal (1987:15), the discussion about the meaning of the vocabulary and how the meaning of a word relates to the meaning of other words (word sense) is discussed in semantics.

The literal meaning of semantics itself is the study of meaning, but this meaning only appears after the lexemes (basic semantic value) are compiled. Furthermore, discourse as seen in Crystal's diagram (1987:15) does not refer to the discourse analysis. Instead, it refers to the branch of linguistics dealing with the role of contexts (situation, culture, and others) in composing the meaning. This branch of linguistics is called pragmatics. The interrelatedness of each branch of linguistics can be seen in the Figure 1 below:

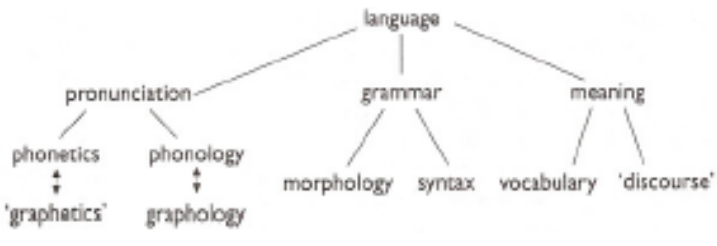

Figure 1. The Branches of Linguistics.

\subsection{Translation}

Translation, in a simple sense, can be described as the process of transferring message from the source language to the target language perfectly. To accommodate the academic aspects of translation process, the scholars came with the term translation studies.

Translation studies can be further divided into various branches as seen in the diagram of translation studies branches proposed by Holmes (2000: 172185):

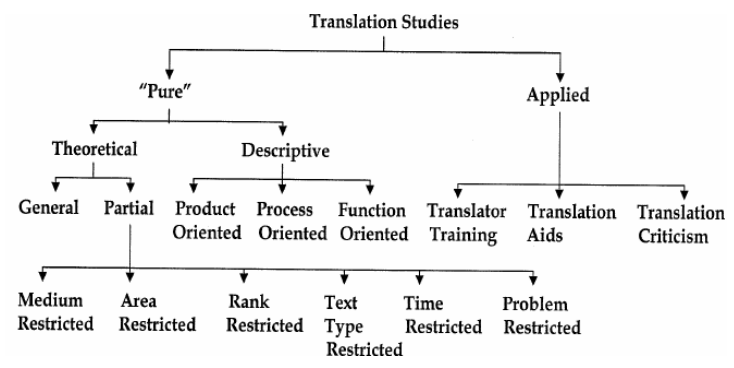

Figure 2. The Branches of Translation Studies.

Based on the Figure 2 above, the authors are focusing more on the "partial translation studies" as this part often connected with the industries, without disregarding the roles of linguistics. The name itself has already reflected that it deals with both theory and practice. "Partial translation studies" is restricted based on its medium, area, rank, types of text, time, and problem. Medium refers to the translator, either human or machine. Area means the pair of the source language and the target language of the translation, for an instance, Bahasa Indonesia and English. Rank refers to the linguistic unit being translated, such as from word to paragraph and so on. Time relates to the process and the history of the theory and practice of the translation. Types of text refer to the types of text being translated, such as business text, subtitling text, and others. Finally, the translation problem refers to the problems faced by the translators during the process of translating the texts. As an example, the translators translating novels must have different problems with those who translate academic text. The 
authors believe that the chosen branch of translation represents the relevance of industries and translation.

\section{RESEARCH METHOD}

The research paradigm used in this article is descriptive qualitative one. This paradigm is used since its basic characteristic shows the ability to unveil unseen information of certain social phenomenon, thus it allows the authors to receive detailed information. Taylor and Bodgan (1998:23) explain that qualitative paradigm is a research procedure that fabricates descriptive data taking form as a research notes or reports of a critical literature review. According to Semi (1993:8), a critical literature review is an on-site research procedure that can be done in one's private room (in-situ). This argument means that a researcher does not need to conduct a field study to gain data and generate discussions. The data and information are gathered through secondary data. The secondary data employed in this study are books related to linguistics, translation, and vocational education.

\section{DISCUSSION}

From the conducted literature review, the authors argue that there is a strong connection between each branch of linguistics and translation studies. The connection appears as theoretical and practical connections.

Firstly, in relation to phonetics and phonology, translation, especially verbal translation, utilizes theory from these branches of linguistics. General people, or maybe linguistics enthusiasts, may not believe that the linguistics study of sounds can also support the development of translation science. Of course, the suitable association is in the field of interpreting, one type of verbal translation. Interpreters can benefit from the theory of language stress learnt in phonetics and phonology. This type of stress is studied under prosodic stress discussion. Take a look at the following example:

"I didn't take the exam yesterday"

The stress on particular word can differentiate meaning, for example if the stress falls on "the" it means that the person takes different exam. Meanwhile, if the stress happens in the word "yesterday" it means that the person takes the exam some other day. Other discussion, such as close and open juncture can also trouble interpreters if they do not know the knowledge of phonetics and phonology. From the examples "nitrate" vs. "night rate", we identify that they have an exceptionally similar sound. If interpreters' minds are caught somewhere, they will easily lose the meaning. That is why, aside from understanding the context, the knowledge of phonetics and phonology is proven crucial in translation studies.

Next, morphology has also certain association with translation science and practice. In morphology, translators can take the benefit from learning the theories of coinage, zero derivation morphemes, word formation, and many more. Take a look at the following examples:

$\begin{array}{ll}\text { (i) } & \text { Ineed to Kleenex it } \\ \text { (ii) } & \text { Love } \\ \text { (iii) } & \text { Bird catcher }\end{array}$

Translators who do not know what "Kleenex" is can fall into the pitfall of using it as a borrowed word. This may confuse the readers even more, especially if they are not familiar with the tissue brand. The phenomenon is called coinage or the creation of a new word. In this case, the word "Kleenex" can mean "clean" or "wipe". In the second example, by understanding morphology, translators can identify if in English, some verbs can be nouns without any addition of a derivational suffix, for example:

$$
\begin{aligned}
& \text { (i) Ilove you } \\
& \text { (ii) Love hurts }
\end{aligned}
$$

The first word acts as a verb and the latter is a noun. Lastly, the third example shows the importance of understanding word formation theory consisting of derivation and compounding. Both words "bird" and "catcher" are the examples of complete words but are being treated as one form. Understanding the theory will help translators to determine whether a word comprising two independent morphemes is or is not meaningful in its sense.

As the study of phrase or sentence formation, syntax is undeniably related to translation studies. To take the benefit even further, the application of syntax is also used in developing machine translation, like Google Translate or Trans tool Software. Garvin (1963:223) suggests that syntax routine is "essential for the efficient solution of the problem of word order for the output". From syntax, translators, especially novice translators, can learn the way to formulate a grammatically correct sentence. Since a sentence is the reflection of a complete thought, it needs a minimum of a subject and predicate. The absence of either will make a sentence fragment (part of sentence, not a sentence). If translators understand this, they will not only be able to make a correct translation, but also be able to identify should there 
are mistakes in the source language. Take a look at the following example:

\section{"The four independent affecting significant positioning'"}

The example is taken from real life example, a translation produced by a student of translation major. From the example, a professional translator will know that is not the example of a complete sentence, since a predicate is missing. Had the student known English syntax, he would have been able to avoid using sentence fragment as the translation of a complete sentence.

Translators must know that a word can have more than one meaning. The phenomenon is often studied in semantics, the branch of linguistics that studies about meaning. Not only that, by studying semantics we can also identify the semantic aspects of a word. Take a look at the following examples:
(i) Bank
(ii) Passed away
(iii) Died
(iv) Curious box
(v) Curious boy

From the first example, the authors are able to identify that the word "bank" can have two meanings, (1) financial institution and (2) the edge of river. If a translator understands the knowledge of semantics, he will avoid being in a rush in translating "I will go to the bank tomorrow", because "bank" is ambiguous. In this case, a translator must check the context, either the deixis or anaphora, to determine its meaning. Meanwhile, the second and third example show us that there is a difference between "passed away" and "died", although both of them refer to the same state or condition. "Passed away" is considered as [+polite] in its semantic features. Studying semantics means that a translator enables him or herself to use "passed away" or "died" in a certain given context. Lastly, in (iv) and (v), the authors argue that the unification of each word (or lexeme in this case) contribute to the change of meaning of the word "curious". "Curious box" means "a box that triggers curiosity", while "curious boy" means "a boy who is being curious". Once again, if a translator understands semantics, he or she will avoid translating "curious box" into "kotak yang penasaran" (a box that is being curious). The discussion itself is often studied in the semantic word sense.

Lastly, studying pragmatics means studying the context where a language takes place. Different context of situation can create different interpretation or meaning. Take a look at the following example:

(i) A: Do you like my coffee?

\author{
B: The food is good \\ A: Have you done your work? \\ B: Not yet.
}

The first example seems showing a failed conversation. It seems that B's response is irrelevant. But by knowing the context, B's response is actually covering B's intention. B shows an innuendo in a language expression. Rather than being straightforward, B tries to shades the fact that B does not like the coffee. This phenomenon is often studied in the cooperative principles or implicatures. Translators, of course, have the flexibility to clear the translation. They can just translate B's expression into "saya tidak suka kopimu" (I don't like the coffee). Of course, this is permissible if they think it can create a maximum translation readability effect.

In the second example, the authors take a conversation sample between a teacher (A) and a student (B). In pragmatics, politeness principles are also being studied. In the context of Indonesia, the use of B's answer is not polite, since B talks to his or her superior or super ordinate. In this case, translator can translate B's answer into "belum, Pak" (not yet, Sir) or "belum, Pak. Saya belum mengerjakan" (no, Sir. I Haven't). To conclude, all of the examples in the discussion are the privileges that can be utilized by translators if they learn linguistics in the first place.

\section{CONCLUSIONS}

Linguistics can give a contribution to industries; even it can develop its own industry, language industry. Translation is regarded as the principal commodity in the aforementioned industry because its flexibility to be affiliated to the manufacturing of goods and service commercialization. Thus, it is advisable to include translation content in the curriculum of Language for Specific Purposes courses. If we only rely on Language for Tourism Purposes or Language for Finance and Banking Purposes, for instance, linguistics theory is not going to be taught, the theory of tourism and banking are.

This article identifies that each branch of linguistics plays a vital contribution in the field of translation science and practice. Therefore, linguistics shows that it can stand proud as a science while also contributes its scientific nature to the development of language or non-language industries. This phenomenon teaches us that translation can be the perfect example of a language/linguistics-based vocational course that can be implemented in the study levels starting from Diploma One (one-year vocational education diploma) to Applied Doctorate. 
Lastly, the authors confirm the shortcomings of the study. One of them is we did not include the response from related stakeholders, for example the perception of the academia members of graduate recruiters. The perception is needed to identify the prospect of translation as a language-based study program or the opportunity given by graduate recruiters to employ graduates who hold the knowledge of translation and ability of translating source to target language. These points are pivotal to the continuation of the study.

\section{REFERENCES}

Cabrera, T. (2017). The translation and interpreting industry in the United States. United States: FASHarvard University.

CBC News. (2017). Workers with no college degree fall further behind than ever. Retrieved from (https://www.cbsnews.com/news/workers-with-nocollege-degree-fall-further-behind-than-ever/

Crystal, D. (1987). Child language, learning, and linguistics (2nd Ed.). London: Edward Arnold.

Garvin, P.I. (1963). Natural language and the computer. New York: McGraw Hill.

Harris, T. (2001). Linguistics in applied linguistics: a historical overview. Journal of English Studies, 3, 99114.

Holmes, J. (2000). The name and nature of translation studies. In L. Venuti (Ed.). The Translation Studies Reade. London and New York: Routledge.

Maulana, R. (2017, December 6). Pelaut Indonesia Terancam Menganggur. Retrieved from https://ekonomi.bisnis.com/read/20171206/98/715803/ pelaut-indonesia-terancam-menganggur

Nugroho, R.A., Septemuryantoro, S.A. \& Lewa, A.H. (2017). Penerjemahan: sebuah cara untuk meningkatkan kualitas pariwisata Indonesia. In Seminar Nasional Multidisiplin Ilmu (SENDI-U). Universitas Stikubank: Semarang.

Semi, A. (1993). Metode Penelitian Sastra. Bandung: Angkasa.

Taylor, S.J. and Bogdan, R. (1998). Introduction to qualitative research methods: a guidebook and resource (3rd Ed.). New Jersey: John Wiley \& Sons Inc. 